followed by the editors of "Flora Malesiana", in which some hundreds of pages have been devoted to introductory matter in each of the two volumes so far published. It is understood, however, that Mr. Exell proposes to rectify this in a separate work.

The lay-out of the general text is a compromise between completeness and utility. The descriptions of families, genera and species have been pruned to essentials, with emphasis on characters that are regarded as diagnostic for each category. References to the literature are also pruned to avoid mere repetitions ; in the case of genera only the original place of publication is given, though many readers might have been pleased to have also a reference to a recommended later work. No reference at all is given for families. Specimen citation also is limited to a single specimen from each of the large areas marked on the folded map provided in a cover pocket, and this is followed by a brief indication of total distribution and habitat.

Dichotomous keys to genera and to species need to be tested over a long period before their true value can be assessed, but it is usually possible to estimate their workability by inspection. In this Flora considerable pains have been taken to use absolute contrasting characters ; mere size differences have been used but rarely. Such treatment inspires a confidence which in the tests I have made has been shown to be well founded.

The text and illustrations have been carefully edited, and typographical errors are few and unimportant ; even on p. 332, where the two lines appearing at the top of the page have jumped from the bottom, no inconvenience will be caused. The book is dedicated to the memory of the pioneer collectors in the area, Loureiro, Baines and Kirk. Everyone concerned is to be congratulated on the production of a really useful modern Flora.

A. A. BuLlock

\section{CELLS AND THEIR ENVIRONMENT}

Cell, Organism and Milieu

Edited by Prof. Dorothea Rudnick. (Seventeenth Symposium on the Society for the Study of Development and Growth.) Pp. v+326. (Now York: The Ronald Press Company, 1959.) 8 dollars.

The Relationship between Nucleus and Cytoplasm Proceedings of the Symposium held June 9-13, 1958, at l'Université Libre de Bruxelles, Belgium. Edited by Dr. R. J. C. Harris. (Experimental Cell Research, Supplement 6.) Pp. viii +276. (New York : Academic Press, Inc., 1959.) Cloth bound 12 dollars ; paper bound 10 dollars.

$7 \mathrm{HE}$ value of symposia increases with the amount of organization and integration of the topics which are discussed, and, all too frequently, so-called symposia become exercising grounds for well-trained hobby-horses. In "Cell, Organism and Milieu" are gathered together ten papers given at the seventeenth symposium of the Society for the Study of Development and Growth. Certainly the papers all deal with aspects of development or growth, but that is almost the beginning and the end of their connexion with each other. The book has little more coherence than a single volume from almost any scientific journal. Individually some of the papers are of great interest, but it is unlikely that they will all appeal equally to any one reader.
A review article on the physiology and biochemistry of the mammalian blastocyst rubs shoulders with papers on auxins in relation to fruit-growth and on polyploidy in root development. The first paper in the symposium, by Wilde, makes some attempt at a synthesis of the actions of some of the internal and external biochemical factors on the behaviour and development of cells, and the article ends with a description of the remarkable formation of hybrid multinucleate muscle fibres by the fusion of the cytoplasms of mouse and chick myoblasts. HoffmannBerling directs attention to the similarities and differences among the various cellular elements responsible for muscular contraction and other forms of cell movement, and emphasizes by models the universality of the relationship between adenosine triphosphate and contractile proteins. The problems of contraction and the control of contractile processes are taken up again by Csapo in relation to uterine muscle. This involves a discussion of the actions of the gonadal steroids on the cell membranes of the uterine muscle. Moog continues with a discussion of the action of cortisol on the development and activity of phosphatases, and Schneiderman and Gilbert make the suggestion that the 'juvenile hormone' in insect development is a steroid. Finally, a paper by Loomis emphasizes how science advances in water-tight compartments. The importance of carbon dioxide tension has been part of the stock-in-trade of mammalian physiologists since the days of J. S. Haldane, Sir Joseph Barcroft and L. J. Henderson. Its importance is now emphasized in relation to the growth and development of Hydra and other organisms.

"The Relationship between Nucleus and Cytoplasm" again emphasizes the diversity of approaches to a subject which might at first sight appear to be more restricted. The twenty papers range from a study of truth and artefact in electron-micrographs of the nuclear membrane and the mitotic spindle (Lehmann), and of the various cytomembranes and their associated granules (Bernhard), through the fascinat. ing story of the injection of ordered genetic material into bacteria during the mating process of Escherichia coli (Jacob), the results of the transfer of nuclei of different ages of embryo (Fischberg, Gurdon and Elsdale) and of different species (Moore) to enucleate ova, to studies of the different cytochemically dis. tinguishable constituents of the nucleus during development and in different functional states of a wide variety of cells (Alfert). Other papers include one on the use of autoradiographs to determine the pattern of keratin synthesis in an epithelium by the use of sulphur-35-DL-cystine, in which there is some evidence that the nucleus is the first part of the cell to be involved (Pelc), another on their use in the synthesis of chromosome material (Ficq, Pavan and Brachet), and another on the use of chromatography to determine the patterns of amino-acids which develop in normal sea-urchin embryos and in those resulting from interspecific crosses. In the last, the amino-acid pattern is shown to be primarily maternal, even though paternal morphological characters may have appeared.

The dominant note which resounds from both symposia is that cellular behaviour and development result from a very intimate inter-relationship between nucleus, cytoplasm and environment, and that, cells can no longer be regarded as being dominated entirely by nuelear influences.

E. N. WHLMER 